
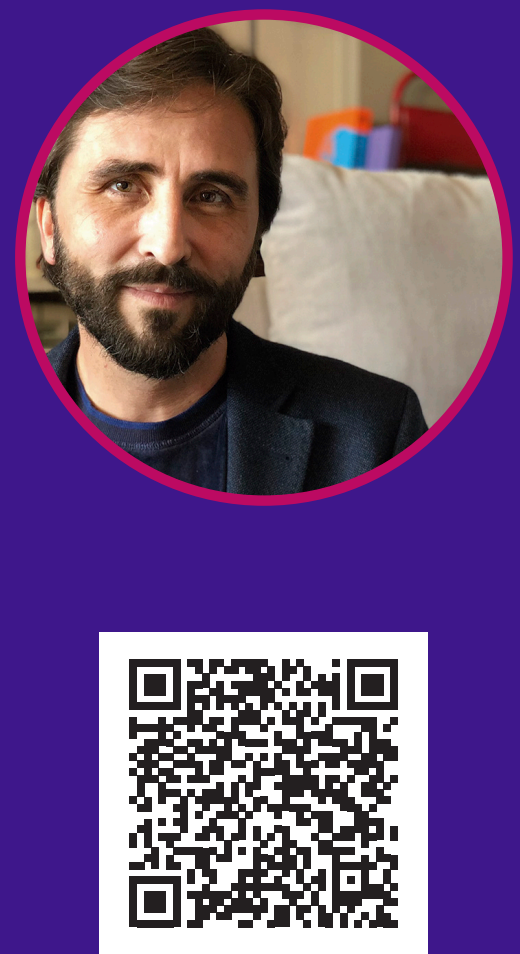

\section{La comunicación política en la era de la desintermediación}

\author{
Political communication in the age of disintermediation
}

\section{Dr. Ignacio Jiménez Soler}

Director de desarrollo de comunicación corporativa de Telefónica i.jimenez.soler@gmail.com
Recibido: 27 de mayo de 2018.

Aceptado: 17 de junio de 2018.
Received: May 27th 2018.

Accepted: June 17th 2018.

\footnotetext{
cc) (†) $\ominus$ Esta obra está bajo una licencia internacional Creative Commons Atribución-NoComercial-SinDerivadas 4.0.
}

DOI: https://doi.org/10.21555/rpc.voi1.2290

Cómo citar: Jiménez Soler, I. (2019). La comunicación política en la era de la desintermediación. RPC, 1(1), 18-25. https://doi.org/10.21555/rpc.voi1.2290

Revista Panamericana de Comunicación, Año 1, N. 1, enero-diciembre 2019, pp. 18 -25.

\section{RESUMEN}

Desarrollar estrategias de comunicación de éxito hoy pasa por desintermediar. Durante el siglo XX, las bases de cualquier actividad de comunicación estaban en pagar por estar (la publicidad tradicional y el paid media actual) o convertirse en noticia en los medios (las relaciones públicas que tomaron el control de la política desde los años 50 en Estados Unidos). Hoy, ambas líneas de trabajo son simplemente dos elementos más de las estrategias de comunicación que han encontrado en los algoritmos su nuevo intermediario. Para tener éxito, hay que salir a buscar a las audiencias, para hacerlo con éxito, hay que conocer bien a la audiencia. La tecnología nos permite trabajar en esta línea, pero a la vez plantea nuevos retos. En este artículo analizo este fenómeno en el marco de la comunicación política.

Palabras-clave: Comunicación política, Desintermediación

\section{ABSTRACT}

Today, developing successful communication strategies is dependent on disintermediation. During the 20th century, communication activities revolved around paying to ensure presence (traditional advertising and current paid media) or appearing in the media as news (public relations that took control over politics in the 1950's in the United States). Today, these two lines are simply elements of a range of communication strategies mediated by algorithms. In order to be successful, audiences must be reached; and, in order to do so successfully, they must be properly understood. Technology helps us to do just this, and yet it poses new challenges. This paper discusses them, in the framework of political communication.

Key Words: Political communication, Disintermediation 
V arios fenómenos impactan y afectan a la comunicación política:

Fenómeno 1. La industria de los medios, tal cual la hemos conocido hasta ahora, se desintegra. Este proceso de desintegración es asimétrico y está llegando antes a unas zonas que a otras, pero llegará. De cada dólar que se invirtió en publicidad en el año 2017, los formatos digitales se han llevado 77 céntimos, 14 céntimos han ido a parar a la televisióny 9 al resto de medios. De toda la inversión en digital, el 52\% fue a parar a Google, el 38\% a Facebook y el 10\% se repartió entre los otros actores digitales.

Fenómeno 2. La televisión en abierto o cable y su consumo lineal es cosa de mayores de 60 años. En su defecto, el consumo bajo demanda de canales de entretenimiento y pago en el colectivo millennial y de 35 a 55 años, es una realidad. Los menores de 20 años, se unen progresivamente a ese fenómeno, pero su atención la centran en YouTube, Sanpchat e Instagram.

Fenómeno 3. El acceso a la información es desestructurado y se materializa en lo que la gente recibe y comparte en redes sociales y en las búsquedas de Google.

Estos tres fenómenos se sintetizan en una destrucción del tejido industrial de los medios y en una competencia atroz por atraer la atención de los ciudadanos. Para hacer comunicación en general y comunicación política en particular, hay que tener en cuenta este contexto. Y este contexto debe ser el punto de partida para cualquier estratega de la comunicación que aspire a gestionar con éxito el mayor reto que hoy tienen los comunicadores: ser relevantes en un entorno fragmentado en miríadas de mensajes, canales y audiencias y hacerlo además robando cuota de atención al usuario.

Las claves para generar una buena estrategia de comunicación política en este entorno pasan por ganar relevancia siendo interesante 0 , si no puedes lograr que tu candidato sea siempre interesante, por lo menos haz que lo que diga sea útil para la ciudadanía. Siendo interesante o útil, marcarás la agenda. Sí, la agenda puede marcarse siendo llamativo o histriónico, pero eso no es conveniente a medio y largo plazo. No hay fin más acelerado para un político que superar a su propia caricatura. El buen estratega de comunicación debe aplicar siempre la máxima de que llamar la atención no siempre es pertinente.

Además de esto, otra de las claves para armar buenas estrategias de comunicación es la consistencia. Una consistencia clara en el fondo de los mensajes, pero también en la forma. La máxima expresión de la consistencia en la forma de los mensajes es el lema de campaña. Acuñar un buen lema no es más que el paso intermedio entre tener un buen propósito que se declina en un lema y que a su vez deriva en líneas argumentales y de acción. El fondo solamente se hace material si se repite muchas veces, por muchos canales y en diferentes formatos.

La tercera clave para afianzar una buena estrategia de comunicación política pasa por responder a una pregunta muy esencial ¿Por qué? ¿Cuál es el por qué que propicia que un votante se incline por un candidato y no por otro? Las estrategias de campaña que responden a esta pregunta son ganadoras, son las que generan mejores lemas y son las que declinan con más facilidad mensajes que conectan emocional y racionalmente con la base electoral.

Las claves hay que acuñarlas, pero también hay que activarlas y hoy el escaparate de los medios de comunicación ya no es suficiente, sigue siendo importante, pero no es suficiente. Hay que combinar estrategias EPO, aquellas que combinan de manera eficiente el earned, el paid y el owned media (en sus acepciones en inglés). Invertir de manera eficiente por mostrar los mensajes, marcar la agenda con el contenido propio y gestionar con inteligencia la conversión de ese contenido propio en un hecho noticioso que entre en la agenda de los medios. Esa sinergia hoy es el seguro de la relevancia para abrirse paso a través del millonario enjambre de mensajes que circula sin control en redes, medios y contenidos indexados.

Los comunicadores tienen que dedicar más tiempo a la investigación y al análisis para desentrañar el corazón de los fenómenos que afectan a su trabajo. Los tres fenómenos enunciados antes, tienen una raíz clara en los comportamientos sociales y son los comportamientos sociales los que marcan el camino de cómo debe ser la comunicación eficiente. En este mundo complejo y cambiante hay un enemigo muy claro: 
el espejismo de que hay que ser notorio cueste lo que cueste y a corto plazo. El estratega de comunicación que aguante este envite y sepa llevar a sus clientes por este camino, logrará la relevancia, la credibilidad y, lo más importante en estos tiempos, la confianza.

\section{EL ALGORITMO, EL NUEVO INTERMEDIARIO}

Tenemos el mejor acceso a la información desde que la humanidad existe y somos más amorfos que nunca. No hablo de una cuestión formal. Nuestra capacidad crítica se va deformando en tanto en cuanto necesitamos un mayor esfuerzo para entender lo que sucede a nuestro alrededor. Vivimos instalados en la idea de que saber algo ya nos da el pasaporte al entendimiento, y nada más lejos de la realidad. Saber no es entender. Opinar no es lo mismo que tener criterio sobre algo y, mientras eso sucede, hay que alertar sobre los riesgos de esta deformación cognitiva que nos hace más vulnerables que nuca a la manipulación.

En noviembre de 2017, en Internet había más de mil doscientos millones de websites activos. A este increíble volumen de canales debemos unirle los medios de comunicación tradicionales (prensa, radio y televisión) y la fuente más antigua de acceso al conocimiento, los libros y la tradición hablada.

Tenemos que hacer autocrítica con honestidad: una corriente de deformidad crítica nos asola. Tener el acceso a la información no nos otorga el saber. Cómo manejamos los canales, cómo discriminamos las fuentes de información y cómo discriminamos lo bueno de lo malo, requiere de un esfuerzo enorme que muy pocos son capaces de hacer. Si a esto le unimos el efecto del Internet de las Cosas (IoT o el Internet of Things), ese concepto acuñado en 1999 por Kevin Ashton, cofundador del Auto ID Center del MIT, según el cual habrá más objetos o cosas conectados a Internet que personas, la calidad real de nuestro entendimiento sobre las causas y efectos lo que sucede en nuestro mundo puede ser extremadamente baja.

Esta suerte de predicción ya se está viendo acelerada por otro factor paradójico. Se trata de la dictadura del algoritmo. Me explico. Si Internet, si las posibilidades del hipervínculo y de la conversación mul- tidireccional de las redes sociales nos han permitido desintermediar la relación con las fuentes tradicionales que antes de manera hegemónica nos proporcionaban información (especialmente los medios de comunicación y centros tradicionales de conocimiento), los continuos cambios en los algoritmos que afectan a los resultados de las búsquedas en Google o lo que Facebook, Instagram o Twitter, esos cambios inciden en qué debe aparecer en nuestro muro o en nuestra corriente de información. La dictadura del algoritmo hace que perdamos muchas opciones de llegar a datos e información que podría ser más práctica, más relevante o más útil. Sin embargo, el mero hecho de que estos nuevos intermediarios han decidido que "eso" que vemos es lo que "necesitamos" ver, provoca fenómenos en masa de aislamiento grupal. Este efecto paradójico que podríamos llamar 'fenómeno de amplitud estrecha' es un hándicap más que afectará a nuestra capacidad de forjarnos criterios sobre las cosas. El activista Eli Pariser ${ }^{1}$, ya habló en 2009 del concepto 'filtro burbuja' para referirse a la navegación a medida o a los contenidos customizados en Internet.

Es verdad que, hasta la irrupción de Google y de las redes sociales, el intermediario o el gatekeeper del contenido decidía qué mostrar, qué publicar sabiendo que fuera había una audiencia dispuesta a escuchar dócilmente aquello que los guardianes de la fuente habían decidido que era importante. Esta teoría que McCombs y Shaw ${ }^{2}$ bautizaron como la agenda setting, se ha visto superada por una conversación que aspira a ser global y que ha dejado a los tradicionalistas aguantando una puerta por la que, en pocos años, nadie entrará porque todo el mundo ha aprendido a sortearla y llegar a ver las miserias del que antes ejercía de guardián.

Esta imagen, muy similar al efecto real generado por la crisis de los refugiados sirios, la sintetizó de manera brillante el humorista gráfico Kap, Jaume Capdevila, que ganó en 2015 el Press Cartoon Europe ${ }^{3}$. Esa

\footnotetext{
1 https://www.opensocietyfoundations.org/people/eli-pariser

2 McCombs, M. y Shaw, D. (1972): "The agenda setting function of mass media”. Public Opinion Quarterly, 36: 176-187.

3 http://www.lavanguardia.com/cultura/20160218/302264221963/kap-gana-press- cartoon-europe-mejor-vineta.html
} 
imagen metáfora de la avalancha es aplicable perfectamente a la oleada de interconexión masiva que ha hecho saltar por los aires los flujos de comunicación y acceso al conocimiento que marcaron el siglo XX.

Si hiciéramos un análisis fino y comparásemos mundos pasados con el que vivimos hoy, veríamos que lo que ha cambiado es meramente formal. Las corrientes internas que condicionan los resortes básicos de la comunicación interpersonal son idénticos: flujos de conversación que se articulan en comunidades, tradición oral y el conocimiento profundo y movilizador concentrado en aquellos que son capaces de hacer un esfuerzo para atraparlo, interpretarlo, fijarlo y divulgarlo.

Hoy, estos elementos permanecen, lo que sucede es que los antiguos nodos de conversación antes aislados, hoy se articulan con rapidez gracias a la tecnología, generando una conversación que puede ser local, regional, global, temática, instruida, dividida o insustancial.

La tradición oral y el contar historias se ha sofisticado. Hoy se articulan en torno a técnicas narrativas en las que el vídeo fácilmente compartible se ha convertido en el gran protagonista de la narrativa del mundo actual.

La información dura, la que requiere verdaderos esfuerzos de quien quiere aprehenderla, sigue ahí. Lo que sucede es que antes residía en monasterios, palacios y luego universidades, y hoy está al alcance de cualquiera. Aquí reside uno de los verdaderos problemas auto perceptivos de nuestra época: tener acceso a la información general o al conocimiento en particular, no significa que lo hayamos aprehendido o que entendamos o conozcamos mejor el mundo y las cosas que en él suceden. Adquirir criterio sobre las cosas requiere de un grandísimo esfuerzo. Un esfuerzo que nunca fue fácil que lo hicieran las grandes masas de personas (pensamiento colectivo-pensamiento masa) y que hoy tampoco van a hacer.

Probablemente hoy, hacer este esfuerzo, sea más difícil que nunca por el efecto superficial que provoca la acción de navegar sobre contenidos hipervinculados. Esto genera un salto continuo, un picoteo frugal y continuo de pequeños fragmentos de información. Un viaje que no siempre tiene el rigor como hilo conductor y sí, el contenido relacionado. Este efecto de superficia- lidad genera un efecto de creencia de que todo está en nuestra mano, de que somos poderosos, de que tenemos el control de la situación. Es verdad que lo que sucede cuando navegamos en Internet tiene un punto mágico y perverso que en cierto modo enajena nuestra verdadera naturaleza acomodaticia en lo que a actitud mental hacia el conocimiento se refiere.

El concepto de opinión pública, mil veces estudiado en el siglo XX, hay que revisitarlo y reformularlo porque hoy ya ha adquirido una dimensión diferente. Si la opinión pública siempre ha sido un espejismo de saber, hoy probablemente sea algo más medible, aunque su naturaleza sigue siendo la de un sucedáneo del conocer, un primo lejano del criterio. Durante el siglo XX los medios de comunicación de masas propiciaron el nacimiento de la opinión pública como una suerte de saber aceptado y generalizado. Este fenómeno espoleó los efectos de la espiral de silencio. Los focos divergentes de la opinión pública añadieron más aislamiento a su naturaleza ya de por sí minoritaria. Este efecto se ha agudizado más con la explosión de las redes sociales, que han permitido aflorar núcleos de reivindicación y actividad, muchos de ellos cargados de emoción y efectismo, pero de escasa racionalidad que han crecido hasta convertirse en tendencias mayoritarias de opinión.

Este fenómeno es en esencia positivo porque debería enriquecer el debate social. Pero que pequeños reductos de posicionamiento terminen convirtiéndose en corriente, no debe llevarnos a asumir que son legítimos o que están fundados en premisas válidas. A la potencia que una imagen o una noticia imprimía a un acontecimiento, hoy se le une el efecto viral de cualquier reivindicación o imagen lacrimógena, tierna o lisonjera y este tridente despista y confunde sobre la realidad de las cosas. Todo esto está generando un efecto amalgama de percepciones al que hay que unirle un efecto adicional y nuevo: el de la nueva intermediación.

Anjana Ahuja, analista y columnista habitual en el periódico británico Financial Times, escribió sobre el fenómeno llamado digital Gerrymanderi ${ }^{4}$. El fenómeno Gerrymandering es un término que se usa en ciencia política para referirse a la manipulación de las cir-

4 https://www.ft.com/content/1a4e85c8-a1a6-11e6-891e-abe238dee8e2 
cunscripciones electorales de un territorio, uniéndolas, dividiéndolas o asociándolas, con el objeto de producir un efecto determinado sobre los resultados electorales. En este caso, la analista británica lo usa para referirse al efecto que Google puede producir en las búsquedas que la gente hace sobre determinados conceptos. Anjana Ahuja escribió su artículo para Financial Times una semana antes de las elecciones norteamericanas en las que Hillary Clinton y Donald Trump se disputaban la presidencia de los Estados Unidos. Según la autora, durante esos días previos a las elecciones, cuando de manera arbitraria comenzabas a escribir en el buscador conceptos como who (quién), what (qué) o where (dónde), lo que el buscador arrojaba era "who is donald trump"; "what does trump means?; "where do i vote". La pregunta obligada es si estas sugerencias y posicionamiento de conceptos responde a la demanda de los usuarios o simplemente el nuevo intermediario, Google, puede tener algún interés en influir o condicionar la percepción y por lo tanto el voto final de los electores norteamericanos. Según desvela la autora en el artículo, diferentes investigaciones han concluido que la manipulación de los motores de búsqueda ${ }^{5}$ implica un control mental a escala masiva.

En 1955, dos sociólogos Ilamados Paul Lazarsfeld y Elihu Katz, elaboraron el modelo de la comunicación en dos pasos o también conocida como two-step flow of communication. Este modelo se basaba en que la mayoría de las personas construía sus opiniones bajo la influencia de los líderes de opinión y estos a su vez la formaban a partir de los contenidos de los medios de comunicación de masas.

Los trabajos de Lazarsfeld y Katz impactaron de tal manera en la política y las empresas americanas, que impulsaron un modelo de relaciones públicas e influencia basado en articular las relaciones de las organizaciones políticas y empresariales con los medios de comunicación de manera sólida, casi simbiótica, a la vez que se implantaba la figura del spin doctor como muñidor de consignas que eran asumidas rápidamente por la sociedad. ¿Qué supuso esto durante más de sesenta

5 http://www.sciencemag.org/news/2015/08/internet-search-engines-may-be- influencing-elections años? Que existió un estado de opinión de arriba abajo muy afianzado y que aseguraba un casi absoluto control. Este modelo ha sido posible mientras la industria de los medios ha sido estable y mientras todos los actores sociales han permanecido en la base de la pirámide en el ciclo de comunicación.

En ciencias, las verdades tienen fecha de caducidad. Esto también aplica a las ciencias sociales. En el año 2000, cuarenta y cinco años más tarde, el propio Katz revisó su modelo y vaticinó con enorme precisión que la comunicación de masas del futuro sería fragmentada, amorfa y basada en conversaciones. Visto desde la perspectiva actual, no parece novedoso, sin embargo hay que darle el valor a la visión de Katz, que básicamente anticipó el impacto de las redes sociales como eje fundamental de la comunicación.

Hoy, estamos en un momento de enorme dispersión, tanto de mensajes como de canales; la industria de los medios de comunicación está inmersa en una crisis de modelo industrial pero también en una crisis de confianza. Según el Trust Barometer que anualmente publica Edelman, la gente confía más en lo que busca y encuentra en Internet que en los medios de comunicación. No sólo eso, si no que durante los dos últimos años, la gente también confía más en lo que le dicen sus amigos y seguidores (o seguidos) en las redes sociales que lo que sale de los medios de comunicación; pero esto no es todo, desde 2014 hasta ahora, lo que surge, se publica y distribuye en medios propios (véase, cualquier información elaboradora por organizaciones públicas y privadas), va camino de superar también en niveles de confianza a la que suscitan los medios de comunicación y ya supera a las redes sociales.

A todo esto hay que añadirle que el volumen de canales en los que se publican contenidos ha generado una durísima competencia para competir por el tráfico y estar ahí donde la gente busca y hacerlo con contenido relevante e interesante. Aquí está la clave: hoy, si una organización o un personaje quiere ser relevante, debe compatibilizar un modelo de comunicación tradicional con otro donde la propia organización produzca contenido propio y de calidad, desarrolle una buena política de distribución para formar parte de las conversaciones de la gente y sobre todo posicionar bien el contenido. 
Este es el cambio de paradigma. Las organizaciones y personajes públicos pueden optar por desintermediar parcial o casi totalmente a los medios de comunicación y tener voz propia, a la par que influyen en ellos. Pero ahora tienen que vérselas con el otro intermediario, el algoritmo, que hace que tu voz, tu contenido sea relevante o no y que esté allí donde la gente busca, o no. Ahí está la batalla por la relevancia.

\section{MENTIRAS}

En diciembre de 2016, una joven de 17 años fue violada y asesinada en Alemania por un varón de origen afgano. Poco después del atroz asesinato, comenzó a circular en Facebook una supuesta cita de la diputada y exministra alemana Renata Künast en la que se le atribuía haber dicho "Sí, el joven refugiado estaba traumatizado y asesinó. Pero tenemos que ayudarle de todas formas". Al texto, para darle una pátina de verosimilitud, se le adjuntaba un logotipo del periódico Süddeutsche Zeitung. El tema importante es que la cita nunca existió y nunca la dijo la ex ministra Künast, pero se compartió de manera masiva y el daño fue irremediable, al menos parcialmente, hasta que Künast logró que Facebook eliminase la cita. Lo consiguió, tal y como ella ha reconocido públicamente, porque su estatus político le permitió llegar a agilizar el proceso de una manera probablemente inalcanzable o mucho más difícil para cualquier ciudadano.

Este caso es solo uno de miles. El fenómeno de publicar textos con contenidos falsos y distribuirlos a través de canales sociales es un fenómeno que no va a cesar. Va a crecer y solamente un exceso de regulación y leyes pondrá una serie de puertas al campo que servirán de poco. Básicamente serán motivo de regocijo y denuncia por parte de una industria, la de los medios de comunicación, en plena decadencia económica, de influencia y de relevancia. Pero, relativicemos, ni antes de esta avalancha de contenidos falsos o seriamente contaminados la verdad era patrimonio de los medios de comunicación, ni hoy la mentira es intrínseca a cualquier canal de difusión.

Vivimos una era de fragmentación de canales y audiencias. Casi podríamos decir que hay tantos cana- les susceptibles de emitir como destinatarios susceptibles de recibir contenido y, en este magma de millones de conexiones y flujos de información ¿Quién es capaz de garantizar la verdad? ¿Quién tiene el patrimonio de la objetividad y de la veracidad? Todo es una enorme paradoja. Hoy no hay nada tan directo, descarnado y objetivo como un vídeo en streaming dando cuenta de algo que está sucediendo y a la vez no hay tantas opciones de modificar la realidad y ponerle filtros de verdad a mentiras monumentales. Mi pronóstico de la cosa es de extrema gravedad. La única esperanza es uno mismo si es capaz de relativizar al máximo todo hasta el punto de que solamente el verdadero esfuerzo por entender los porqués de las cosas es lo que puede evitar nuestra deformidad cognitiva. Una deformidad con una doble causa, el exceso de impactos y por ende la imposibilidad de discriminar entre lo verdadero y lo falso y una segunda, la deriva viscosa a la que nos aboca el pensamiento masivo fácilmente compartible.

El 25 de noviembre de 2010, el dibujante El Roto, ponía este texto a una viñeta publicada en el diario El País: Lo malo de esta edad de oro de la comunicación y la información es que no hay manera de saber lo que pasa. Muchos años antes, Ortega y Gasset, en la meditación preliminar de su Meditaciones del Quijote y otros ensayos", afirmaba que "El mundo profundo es tan claro como el superficial, solo que exige más de nosotros". La virtud del filósofo emana de marcar el porqué de las cosas:

Quien quiera enseñarnos una verdad que nos la diga: simplemente que aluda a ella con un breve gesto, gesto que incide en el aire una ideal trayectoria, deslizándonos por la cual lleguemos nosotros mismos hasta los pies de la nueva verdad. Las verdades, una vez sabidas, adquieren una costa utilitaria; no nos interesan ya como verdades, sino como recetas útiles. Es pura iluminación subitánea que caracteriza a la verdad, tiénela esta sólo en el instante de su descubrimiento. Por esto su nombre girego, alétheia, significó originariamente lo mismo que después la palabra apocalipsis, es decir, descubrimiento, revelación, propiamente develación quitar

6 Meditaciones del Quijote y otros ensayos. Alianza Editorial. Madrid 2014. Primera edición 1914 (Pág. 54). 
un velo o cubridor. Quien quiera enseñarnos una verdad, que nos sitúe de modo que la descubramos nosotros (Ortega y Gasset, 1914; 54)

Este pasaje sintetiza filosóficamente la función del periodismo que hoy se desintegra anegada por el caudal de contenidos e informaciones que silban como balas desde nuestros dispositivos electrónicos. Casi un siglo después que Ortega y en otro orden de magnitud intelectual, Jeff Jarviss hacía una apología del periodismo como defensa, siendo esta su razón de ser, en un entorno en el que la digitalización, la tecnología, el enorme impacto de los nuevos hábitos en el consumo de la información, han puesto a la industria de los medios, a los periodistas y a su función principal, la defensa de los valores esenciales, al pie de los caballos y convierten su trabajo en "polvo digital"7.

Sabemos que vivimos en medio de una ventisca de contenidos. La gran mayoría de ellos pasan desapercibidos, pero permanecen zombies, flotando en el hiperespacio de la red y allí pueden permanecer latentes o durmientes durante años o de por vida o, repentinamente, recobran vida porque fueron buenos vaticinios de algo, porque el tiempo ha terminado otorgándoles sentido o razón. Esto sucede poco y sucederá menos, pero es posible. Solamente aquellos que tienen una carga emocional, divertida o tremendamente polémica, se abren paso temporalmente, son compartidos de forma viral o logran destacar por encima de otros. Ante este panorama, cabe preguntarse por el sentido del periodismo como lo entendíamos hasta ahora 0 , incluso, si esto puede ser considerado periodismo.

El periodismo no es más que una jerarquización de la realidad dentro de la agenda limitada de un canal cuya propiedad está en manos de alguien que convive en un sistema complejo en el que tiene intereses. Por eso, cuando hoy asistimos a debates sobre la necesidad de que permanezcan los medios tal cual existieron durante el siglo XX, es lícito preguntarse por la legitimidad o no de esta industria para acaparar la Ilave de lo que es noticia o no. Lo cierto es que hoy, no es necesaria esa jerarquización, aunque es verdad que ayuda a poner foco. Al igual que cabe preguntarse si en la música tiene sentido sacar álbumes cuando cualquiera puede componer su propia lista de canciones o hacerla pública, también cabe preguntarse por la necesidad de que un ente público o privado jerarquice la realidad. Por lo tanto, la función del periodista y del periodismo está plenamente vigente en tanto en cuanto no tenga por qué aparecer ligada a una industria determinada. El periodismo será tal si es capaz de impactar de forma positiva en la vida de los ciudadanos, y esto es posible independientemente de la fuerza de una industria que lo respalde. Jeff Jarvis afirma que "si no es una defensa, no es periodismo, es decir, que si no se esfuerza por tener un impacto positivo en la vida de los ciudadanos, no es periodismo. Si no ostenta el poder de informar en nombre de los ciudadanos, no es periodismo" $(2015 ; 130)$

Durante el siglo XX, los ciudadanos asistimos a la consolidación, crecimiento e influencia de los medios de comunicación de masas. Estos condicionaron nuestra manera de entender el mundo en tanto en cuanto el mundo que veíamos era el que emanaba de su agenda, no esencialmente el que emanaba de la realidad. Esto implicaba, silenciamientos claros de lo que sucedía en el mundo, bien por omisión o bien por incapacidad de emisión derivada a su vez de su propia limitación de agenda; también implicaba manipulación, bien por los propietarios o bien por los otros poderes que entendieron a la perfección el juego de favores y contra favores para hacer de los medios de comunicación lo que fueron y lo que son hoy en día: una audiencia instrumental condicionada por las fuentes y por la necesidad de supervivencia del sector. Entonces ¿Es más deseable este escenario de mímesis entre poderes o es más deseable este que vivimos ahora de torrentes de contenidos que hacen humanamente inviable el escrutinio de la solvencia y veracidad de lo que hablan? Humildemente pienso que ambos nos llevan al mismo lugar. El primer modelo obligaba a hacer un gran esfuerzo para estar bien informado por omisión de contenidos y el segundo modelo nos obliga a hacer un gran esfuerzo para separar lo bueno de lo malo y llegar al porqué de las cosas. En definitiva, el usuario decide si quiere dejarse arrastrar o emprender con tesón y esfuerzo el camino hacia la esencia de las cosas. Ortega dixit: quien quiera enseñarnos una verdad, que nos sitúe de modo que la descubramos nosotros. \

7 Jeff Jarvis. El fin de los medios de comunicación de masas ¿Cómo serán las noticias del futuro? Gestión 2000. Madrid, 2015. Pág. 122. 


\section{REFERENCIAS}

» Ashton, Kevin (2017). "El propósito del internet de las cosas es beneficiar a los clientes y no a la empresa" En https://www.publinews.gt/gt/tendencias/2017/09/05/kevin-ashton-proposito-del-internet-las-cosas-beneficiar-los-clientes-no-la-empresa.html

» Ahuja, Anjana. How 'digital gerrymandering' can swing the American election

» (s.d.). En https://www.ft.com/content/1a4e85c8-a1a6-11e6-891e-abe238dee8e2 y https://www.ft.com/anjana-ahuja

» Edelman (2017) Trust Barometer (2017) En https://www.edelman.com/research/2017-edelman-trust-barometer

» El humorista gráfico Kap, autor de la mejor viñeta europea del 2015. En http://www.lavanguardia.com/cultura/20160218/302264221963/kap-ga- napress- cartoon-europe-mejor-vineta.html

» Jarvis, Jeff (2015) El fin de los medios de comunicación de masas ¿Cómo serán las noticias del futuro? Madrid, Gestión 2000.

» Lazarsfeld, Paul F. y Katz, Elih (1955). Personal Influence: The Part Played by People in the Flow of Mass Communications. New York. Routledge (2017).

» McCombs, M. y Shaw, D. (1972): "The agenda setting function of mass media". Public Opinion Quarterly, 36: 176-187.

» Ortega y Gasset, José (2014). Meditaciones del Quijote y otros ensayos. Madrid, Alianza Editorial.. Primera edición 1914

» Pariser, Eli (2017). El filtro burbuja. BareIona, Taurus. 